\title{
Development of the first georeferenced map of Rhipicephalus (Boophilus) spp. in Mexico from 1970 to date and prediction of its spatial distribution
}

\author{
Yazmin Alcala-Canto, ${ }^{1}$ Juan Antonio Figueroa-Castillo, ${ }^{1}$ Froylán Ibarra-Velarde, ${ }^{1}$ \\ Yolanda Vera-Montenegro, ${ }^{1}$ María Eugenia Cervantes-Valencia, ${ }^{2}$ Abdelfattah Z.M. Salem, ${ }^{3}$ \\ Jorge Alfredo Cuéllar-Ordaz ${ }^{4}$ \\ ${ }^{1}$ Parasitology Department, Faculty of Veterinary Medicine, National Autonomous University of Mexico, \\ Mexico City; ' $P$ PD Graduate Program in Animal Science and Production, Faculty of Veterinary Medicine, \\ National Autonomous University of Mexico, Mexico City; ${ }^{3}$ Faculty of Veterinary Medicine, National \\ Autonomous University of Mexico State, Toluca; ${ }^{4}$ Faculty of Higher Education Studies Cuautitlán, National \\ Autonomous University of Mexico, Cuautitlán, Mexico
}

\begin{abstract}
The tick genus Ripicephalus (Boophilus), particularly $R$. microplus, is one of the most important ectoparasites that affects livestock health and considered an epidemiological risk because it causes significant economic losses due, mainly, to restrictions in the export of infested animals to several countries. Its spatial distribution has been tied to environmental factors, mainly warm
\end{abstract}

Correspondence: Yazmin Alcala-Canto, Parasitology Department, Faculty of Veterinary Medicine, National Autonomous University of Mexico, Av. Universidad 3000, Coyoacan, Mexico City, 04510, Mexico.

Tel.:0052155562258989.

E-mail: yazmin@unam.mx

Key words: Rhipicephalus (Boophilus) spp; Georeference; GIS; Maxent; Species distribution model; Mexico.

Acknowledgments: climate data provided by the Research Program on Climate Change, Agriculture and Food Security (CCAFS) in this work is greatly acknowledged as well as weekly reports of Is spp. provided by SENASICA-SAGARPA on its public website.

Contributions: the authors contributed equally.

Conflict of interest: the authors declare no potential conflict of interest.

Funding: the authors are grateful to DGAPA-PAPIIT IT200816 for the financial support of this project.

Received for publication: 12 September 2017.

Revision received: 30 January 2018.

Accepted for publication: 7 February 2018.

(C) Copyright Y. Alcala-Canto et al., 2018

Licensee PAGEPress, Italy

Geospatial Health 2018; 13:624

doi:10.4081/gh.2018.624

This article is distributed under the terms of the Creative Commons Attribution Noncommercial License (CC BY-NC 4.0) which permits any noncommercial use, distribution, and reproduction in any medium, provided the original author(s) and source are credited. temperatures and high relative humidity. In this work, we integrated a dataset consisting of 5843 records of Rhipicephalus spp., in Mexico covering close to 50 years to know which environmental variables mostly influence this ticks' distribution. Occurrences were georeferenced using the software DIVA-GIS and the potential current distribution was modelled using the maximum entropy method (Maxent). The algorithm generated a map of high predictive capability (Area under the curve $=0.942$ ), providing the various contribution and permutation importance of the tested variables. Precipitation seasonality, particularly in March, and isothermality were found to be the most significant climate variables in determining the probability of spatial distribution of Rhipicephalus spp. in Mexico (15.7\%, 36.0\% and $11.1 \%$, respectively). Our findings demonstrate that Rhipicephalus has colonized Mexico widely, including areas characterized by different types of climate. We conclude that the Maxent distribution model using Rhipicephalus records and a set of environmental variables can predict the extent of the tick range in this country, information that should support the development of integrated control strategies.

\section{Introduction}

Ticks are distributed worldwide, from the Arctic region to the tropical areas. Most of these species are important disease vectors that affect animal and human health (Wang et al., 2015). Infestation of cattle by ticks of the genus Rhipicephalus (Boophilus) has been reported to negatively impact economy and animal health, mainly because the parasite transmits tick-borne pathogens such as Babesia bovis, B. bigemina or Anaplasma marginale (Rodriguez-Vivas et al., 2017), reduces weight gain, decreases milk and meat production (Jonsson et al., 2008; Mondal et al., 2013), injects toxins, causes blood loss, stress and irritation (Manjunathachar et al., 2014). Likewise, Rhipicephalus spp. interferes with domestic and international trade due to restrictions in the export or introduction of infested cattle to areas or countries that have official regulations to control this parasite, for example, the United States (Pérez de León et al., 2012; Giles et al., 2014).

One of the most important factors that determines the survival and distribution of this tick species is climate. In general, regions with warm and humid conditions are suitable for the occurrence and development of Rhipicephalus spp. (Estrada-Peña et al., 
2006b). Ecological and climatologic data, as well as mathematical models, are available to estimate the distribution of potential growth and development of a species. The use of these models increases the understanding of the most important factors that influence the presence or absence of a parasite in a given region (Estrada-Peña et al., 2016; 2006b) and may shed light on the biological capacity of a species to establish and thrive in different climatic regions. This information can be useful to implement geographical planning of prevention activities by targeting areas that are suitable for Rhipicephalus spp. (Estrada-Peña, 2001).

Several previous studies have modelled ecological niches of species using approaches such as the maximum entropy (Maxent) algorithm to estimate the potential distributions of ixodid ticks in the United States, such as Amblyomma americanum (Raghavan et al., 2016) in Kansas, Ixodes scapularis (Johnson et al., 2016) in Minnesota and Dermacentor variabilis (St John et al., 2016). Rhipicephalus microplus and $R$. appendiculatus distributions have been modelled in West Africa (De Clercq et al., 2013; Leta et al., 2013; De Clercq et al., 2015) and the Horn of Africa (Leta et al., 2013), respectively. The distribution of $A$. cajennense and A. sculptum in Brazil has been assessed under present-day and future climate models (Oliveira et al., 2017); whereas suitable habitats for D. marginatus, Haemaphysalis punctata, Ha. sulcata, Hyalomma lusitanicum, Hy. marginatum, I. ricinus, $R$. annulatus and $R$. bursa have been predicted using the same algorithm (Williams et al., 2015).

In Mexico, the official institution for the diagnosis and public reporting of occurrences of Rhipicephalus) spp. is the National Service for Quality, Safety and Agricultural Health of the Secretariat of Agriculture, Livestock, Rural Development, Fisheries and Food (SENASICA), which carries out this responsibility according to the Mexican official regulations for the control of this parasite (SENASICA, 2017). Several studies have published information about the areas in Mexico where the tick has been collected with and noted the different climatic patterns that support Rhipicephalus spp. (Galaviz-Silva et al., 2013; RodriguezVivas et al., 2012; Rodríguez-Vivas et al., 2014b; Sánchez, 2014). However, as far as we currently know, there is not a single dataset including countrywide georeferenced Rhipicephalus locations that would support further modelling studies and make it possible to predict potential spread of the tick prompting veterinarians to take up timely control measures. We report here, for the first time, the georeferenced locations of Rhipicephalus spp. in Mexico for the period 1970-2017 modelling the potential geographic distribution of the tick using its current distribution and data based on a range of environmental parameters.

\section{Materials and Methods}

\section{Data}

A dataset comprising 5751 localities, from where any of the known Rhipicephalus spp. had been reported, was compiled for the period 1970 to 2017. The records included published scientific articles, theses, proceedings from academic and scientific meetings (Solorio-Rivera et al., 1999; Rosado-Aguilar et al., 2008; RosarioCruz et al., 2009; Aguilar-Tipacamú and Rodriguez-Vivas, 2003; Alonso-Díaz et al., 2007a; Alonso-Díaz et al., 2007b; Lopez et al., 2008; Rodríguez et al., 2009; Gaxiola-Camacho et al., 2009;
Pound et al., 2010; Lohmeyer et al., 2011; Rodriguez-Vivas et al., 2011; Aguilar-Tipacamú et al., 2011; Fernández-Salas et al., 2012a; Fernández-Salas et al., 2012b; Fernández-Salas et al., 2012c; Rodriguez-Vivas et al., 2012; Rodriguez-Vivas et al., 2013; Miller et al., 2013; Treviño, 2013; Morales, 2014; RodríguezVivas et al., 2014a; Rodríguez-Vivas et al., 2014b; Sánchez, 2014; Alegria-Lopez et al., 2015) as well as from weekly zoo-sanitary information published online (SENASICA, 2017). Only natural infections were included in the database and Rhipicephalus spp. occurrences were recorded a single time when reported at same location and date.

Nineteen bioclimatic layers representing mean annual temperature (MAT), mean annual precipitation (MAP), seasonality as well as other derived precipitation and temperature-linked variables (Tables 1 and 2) were extracted from the websites of Research Program on Climate Change, Agriculture and Food Security (http://www.ccafs-climate.org) and WorldClim (http://www.worldclim.org). Variables resulting from global land area interpolation of climate point data at the 30 -sec spatial resolution were used to produce an ecological niche model for Rhipicephalus spp. distribution. Coordinates for the 5751 sampling localities were collected and subsequently georeferenced using DIVA-GIS version 7.5 (http://www.diva-gis.org), a software that can also predict species habitat suitability and range changes in response to climate (Hijmans et al., 2001). Rhipicephalus spp. georeferenced occurrence points in Mexico were checked for bias and errors using the DIVA-GIS software.

\section{Species distribution modelling}

The predicted distribution of Rhipicephalus spp. in Mexico under current climate conditions was modelled using Maxent software (Phillips et al., 2006), wich is based on an algorithm that estimates the suitability/unsuitability of a location for the presence of a species based on the distribution of maximum entropy, i.e., closest to uniform supported by the association between presence points and environmental variables (Fand et al., 2014; Qin et al., 2016; Suwannatrai et al., 2017). One of the main advantages of Maxent is that it only requires presence data and environmental layers (continuous or categorical variables) for the study area (Phillips et al., 2009; Stevens and Pfeiffer, 2011). The main rule of partitioning data for modelling the distribution of species dictates that the proportion of testing data follows the equation:

$$
D t=1 /\left[1+(p-1) \frac{1}{2}\right]
$$

where $D t$ is the percentage of test data and $p$ the number of predictor variables (Padilla et al., 2017). The percentage for Maxent training of data consists of $75 \%$ presence points, whereas the remaining $25 \%$ of points are used for validation (Khatchikian et al., 2011). We set the random test percentage to $25 \%$ in the current study to improve the model performance, while the parameters set were the ones included by default when using the Maxent approach. The logistic output format used in this study assigned each grid cell of the study area values ranging from 0 (completely unsuitable) to 1 (fully suitable).

To avoid over-fitting, a series of correlations were conducted to remove redundant variables by extracting the bioclimatic information from randomly generated points. A Pearson's correlation coefficient was estimated by SAS/STAT, v. 9.2 (SAS Institute, Cary, NC, 
USA) for the most ecologically relevant variables for Rhipicephalus, such as temperature and precipitation (Estrada-Peña et al., 2006a). A threshold of $|r|>0.7$ was used to eliminate highly correlated variables (Dormann et al., 2013), e.g., precipitation in the driest quarter (bio14) and precipitation in the driest month (bio17). A subset of biologically representative and uncorrelated bioclimatic variables was selected to run Maxent. To evaluate the true predictive power of the model, 10 runs were performed with a 10 -fold cross-validation procedure to get 10 independent subsets, each with the same number of occurrence points (McQuillan and Rice, 2015). Subsequently, the fit of the model to test data was evaluated with the Area Under the Curve (AUC) of the Receiver Operating Characteristic (ROC) (Fand et al., 2014). The model performance was estimated by creating a ROC plot measuring the area with a range from a random accuracy (0.5) to a perfect discrimination (1.0), i.e., an AUC with a value of 0.5 represents a random model, values between 0.8 and 0.9 represent models with a good fit and values over 0.9 means excellent fit (Stevens and Pfeiffer, 2011). Predictions of Maxent were mapped in DIVA-GIS

\section{Results}

\section{Ripicephalus spp. findings}

A total of 5751 geographical coordinates for the locations of Rhipicephalus spp. were obtained and the georeferenced occurrences depicted in a map of occurrences reported before and after the year 2012 (Figure 1). Most locations were obtained from the publically available, official SENASICA dataset, whereas fewer references reporting natural infestations were extracted from the literature. The dataset was limited to records from 1970 to 2017 because no previous records of this parasite were available.

\section{Spatial distribution}

The model projected by Maxent presented an AUC of 0.942 , which represents a strong fit (Figure 2) and, in agreement with the measurement of variable importance, the highest contributions came from variables prec3 (the March precipitation), bio15 (the seasonal

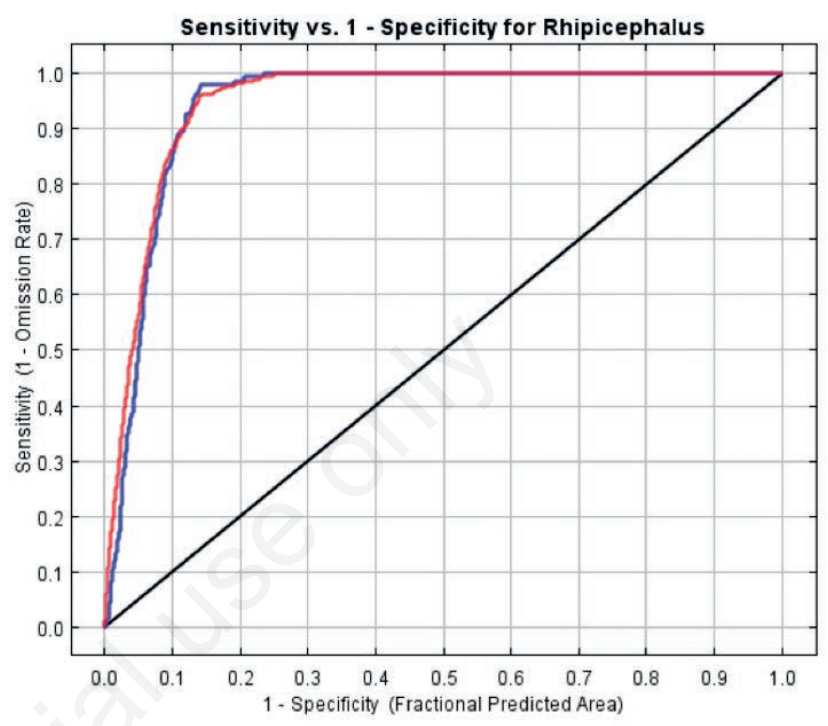

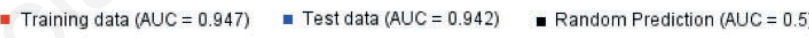

Figure 2. The Receiver operating characteristic curve for training data.

AUC, Area under the curve.

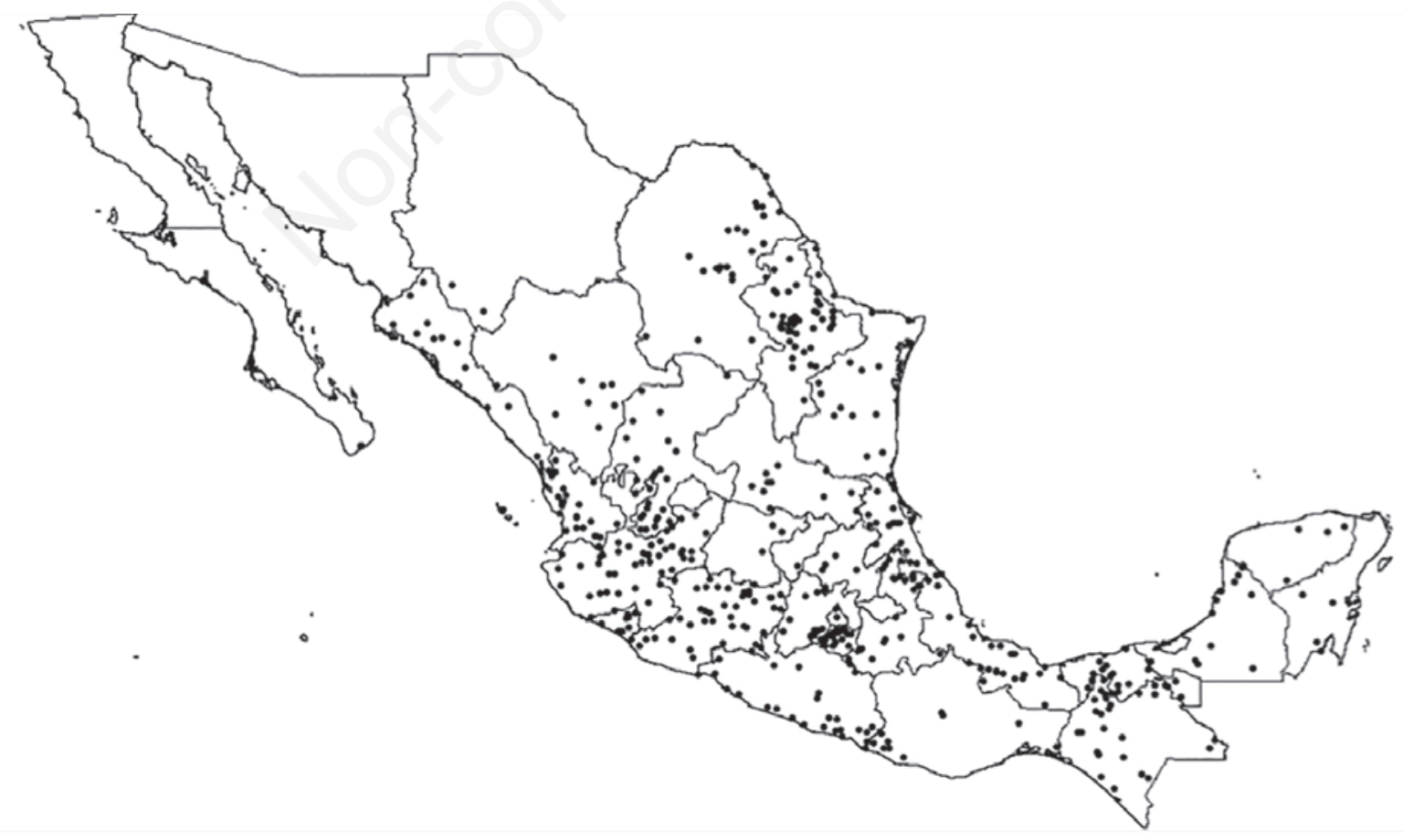

Figure 1. Rhipicephalus spp. occurrences in Mexico from 1970 to 2017. 
precipitation) and bio4 (the seasonal temperatures (Tables 1 and 2), amounting to $36.0 \%, 15.7 \%$ and $11.1 \%$, respectively (Table 3 ). In contrast, bio13 (the precipitation of wettest month), bio1 (the annual mean temperature) and tmean2 (the mean temperature in February), among other variables, neither contributed by percentage nor permutation importance to the distribution of Rhipicephalus spp. under the parameters of this model. The projection of the range distribution model onto Mexico is depicted in a map developed in DIVA-GIS (Figure 3). The most important abiotic factors (prec3, bio15, bio4) influencing the geographic distribution of Rhipicephalus spp. were considered to model the potential current spatial distribution of this parasite (Figure 3). The modelled distribution model showed that the predicted occurrence included the actual distribution of Rhipicephalus spp. in the country.

\section{Discussion}

The climate classification (A-E) made by Enriqueta García (1981), governed by annual and monthly temperatures and precipitation patterns, where type A-climates are warm and humid, B corresponds to dry climates, $\mathrm{C}$ to temperate and humid ones, $\mathrm{D}$ to cold temperatures with intense winters and $\mathrm{E}$ to very cold or polar climates at high altitudes, play an important role for Rhipicephalus spp. occurrences. These ticks have traditionally been linked to climates classified as A and C, and this information is in good agreement with the current and predicted tick distribution map found. In addition, most of the literature reports locations with humid and warm climates (Aguilar-Tipacamú and Rodriguez-Vivas, 2003; Alvarez et al., 2004; Rodríguez-Vivas et al., 2007; Alonso-Díaz et al., 2007b; Gaxiola, 2008). As shown here, the highest contribu-

Table 1. Bioclim layers used in this study.

\begin{tabular}{llll} 
CODE & VARIABLE & CODE & VARIABLE \\
Bio1 & Annual mean temperature & bioll & Mean temperature of the coldest quarter \\
Bio2 & $\begin{array}{l}\text { Mean diurnal range } \\
\text { (Mean of the monthly maximum temperature - minimum temperature) }\end{array}$ & bio12 & Annual precipitation \\
\hline Bio3 & Isothermality (BIO2/BIO7) x 100 & bio13 & Precipitation of the wettest month \\
Bio4 & Temperature seasonality (standard deviation x 100) & bio14 & Precipitation of the driest month \\
\hline Bio5 & Maximum temperature of the warmest month & bio15 & Precipitation seasonality (Variation coefficient) \\
Bio6 & Minimum temperature of the coldest month & biol6 & Precipitation of the wettest quarter \\
\hline Bio7 & Annual temperature range (IO5-BIO6) & bio17 & Precipitation of the driest quarter \\
Bio8 & Mean temperature of the wettest quarter & bio18 & Precipitation of the warmest quarter \\
\hline Bio9 & Mean temperature of the driest quarter & bio19 & Precipitation of the coldest quarter \\
Bio10 & Mean temperature of the warmest quarter & &
\end{tabular}

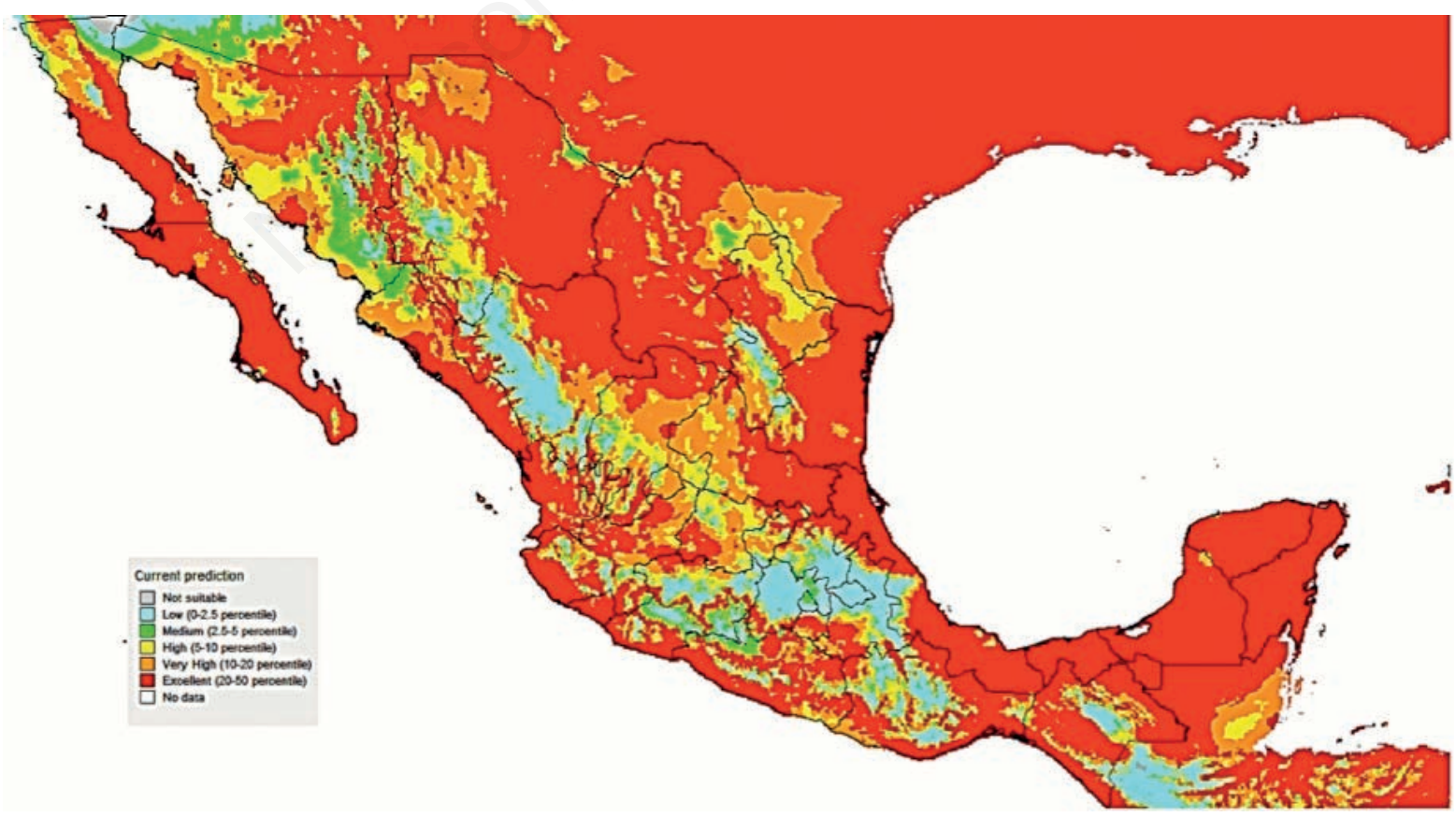

Figure 3. Illustration of the predicted current geographic distribution of Rhipicephalus spp. in Mexico according to the environmental layers with the strongest influence. 
Table 2. Codes for the monthly environmental variables referred to in this study.

\begin{tabular}{|c|c|c|c|c|}
\hline Month & Precipitation & Minimum temperature & Maximum temperature & Mean temperature \\
\hline January & precl & $\operatorname{tmin} 1$ & tmaxl & tmeanl \\
\hline February & Prec2 & $\operatorname{tmin} 2$ & tmax2 & tmean2 \\
\hline March & Prec3 & $\operatorname{tmin} 3$ & tmax3 & tmean3 \\
\hline April & Prec4 & $\operatorname{tmin} 4$ & $\operatorname{tmax} 4$ & tmean4 \\
\hline May & Prec5 & $\operatorname{tmin} 5$ & $\operatorname{tmax} 5$ & tmean5 \\
\hline June & Prec6 & $\operatorname{tmin} 6$ & $\operatorname{tmax6}$ & tmean6 \\
\hline July & Prec7 & tmean7 & $\operatorname{tmax} 7$ & tmean7 \\
\hline August & Prec8 & tmean8 & tmax8 & tmean8 \\
\hline September & Prec9 & tmean 9 & $\operatorname{tmax} 9$ & $\operatorname{tmean} 9$ \\
\hline October & Prec10 & tmean10 & tmax10 & tmean10 \\
\hline November & Precll & tmean11 & tmax11 & tmean11 \\
\hline December & Precl2 & tmean12 & tmax12 & tmean12 \\
\hline
\end{tabular}

tions came from abiotic variables, such as prec3 (March precipitation), bio15 (seasonal precipitation) and bio4 (seasonal temperatures (Tables 1 and 2), amounting to $36.0 \%, 15.7 \%$ and $11.1 \%$, respectively, in determining the probability of occurrence of the species in Mexico (Table 3).

Nevertheless, it is indispensable to rule out the presence of biotic factors that interfere with habitat colonization or invasion potential by the above-mentioned parasites. For example, most of the north-eastern region of Mexico where Rhipicephalus spp. records were obtained is where cattle production has been traditionally carried out, and due to the animal health certifications that the United States of America requests to export cattle to that country, Mexican animal health authorities must perform several examinations to cattle in order to comply with international regulations that request tick-free animals (SENASICA, 2017). The understanding that both habitat suitability and cattle raising coincide with areas where most of the occurrences were reported should prompt researchers and animal health authorities to target risky areas for the geographic planning of preventive measures by Rhipicephalus spp. control programmes.

The evaluation of geographical distribution patterns of this species is important to decrease tick colonization in environmentally suitable areas. The dataset used in the current study included a comprehensive collection of georeferenced records for Rhipicephalus spp. to date (September 2017) and prediction findings identified that tmax5 (the May maximum temperature), bio15 (the precipitation seasonality), and bio5 (the maximum temperature of the warmest month) shape the species distribution patterns, which is a fundamental goal in the fields of ecology and biogeography.

Identifying the factors that shape Rhipicephalus spp. geographic distribution may shed light on where this parasite is able to establish and respond to environmental variables. Its presence in Mexico occurs in regions that, according to our results, can be considered as among the best suited for this tick to develop, i.e. Veracruz, Tabasco, Tamaulipas, Campeche, Yucatán, Quintana Roo and Chiapas. It would be unsafe to state that precipitation is the only factor that restricts habitat suitability of Rhipicephalus spp, yet this finding adds an ecological dimension to further studies aimed to model the potential distribution of this tick.

Therefore, predicting current and future species spatial distri-
Table 3. Estimated relative contributions of the environmental variables to the Maxent model.

\begin{tabular}{lcc} 
Variable* & Contribution \% & Permutation importance \\
prec3 & 36 & 1.1 \\
bio15 & 15.7 & 16.8 \\
\hline bio4 & 11.1 & 11 \\
bio13 & 0 & 0 \\
\hline bio1 & 0 & 0 \\
tmean2 & 0 & 0
\end{tabular}

*Only the three strongest and the three less likely variables shown.

bution may improve the understanding of abiotic factors that provide insight into the suitability of this parasite to survive in several states of Mexico. In the present study, only bioclimatic abiotic factors were considered. Nonetheless, previous findings suggest that biotic factors will be more relevant at a species equatorial range limit; whereas these factors influence high altitude as well as latitude limits (McQuillan and Rice, 2015). While this hypothesis has been discussed in depth, this study did not include information to support or reject macroecological distributions. Still, the potential current distribution tendency of Rhipicephalus spp. shown in our results is consistent with actual locations where this parasite has been reported, such as the state of Tlaxcala and also some localities in Chiapas, where it has not been reported as far as we know.

The fit of 0.942 as measured by the AUC, which is shown in Figure 3, indicates the strong ability of the Maxent algorithm to discriminate between suitable and unsuitable areas for Rhipicephalus spp. occurrence in Mexico (Fand et al., 2014; Suwannatrai et al., 2017). Albeit the best-fitting Maxent model predicts high probabilities of infection occurrence in several regions of the country, it would be unsafe to state that this species will colonize all predicted areas despite suitable climate, because there are variables such as vegetation, type of soil and altitude that will need to be addressed in further studies aimed to model the potential geographic distribution of Rhipicephalus spp.

Many assumptions and limitations are inherent in the present study. For instance, presence-only observations of Rhipicephalus spp. in Mexico collected from an array of sources differed in sam- 
pling effort and geographical focus. Therefore, the present results must be carefully interpreted as these differences could bias models toward areas with easier access for the collection of biological material, or localities with accessible laboratories where expert personnel can properly identify ixodid ticks according to molecular or morphological features. On the other hand, presence-only observations avoid the methodological drawback that absence of species is difficult to demonstrate. However, over- or under-sampling of Rhipicephalus spp. could skew the theoretical habitat preferences of the species (Estrada-Peña, 1999). It would be a mistake to see the current study as definitive. For example, one major limitation is the lack of a specific model for $R$. microplus and one for $R$. annulatus. The spatial distribution of $R$. microplus is influenced by climate mainly in tropical regions but temperate and arid environments can also provide a suitable habitat for this tick species; whereas the latter inhabits arid and temperate climates of Mexico (Rodriguez-Vivas and Domínguez-Alpizar, 1998; Estrada-Peña et al., 2006a; Estrada-Peña and Venzal, 2006; Lohmeyer et al., 2011; Wang et al., 2017). Indeed, different models could provide more reliable results, yet the current database includes reports identified by the federal animal health authorities in Mexico as Boophilus spp. in weekly animal health reports (SENASICA, 2017) and federal regulations (SAGARPA, 2012). Although this aspect of our dataset is limited, we are convinced that this study could support the control of Rhipicephalus spp. in areas with environmental conditions that are highly suitable for the occurrence, development and population growth of this genus of ticks. Further studies should be conducted for assessing the impacts of abiotic factors to identify suitable habitats for Rhipicephalus spp. as well as to improve the predictive power of this species distribution model.

\section{Conclusions}

The results of this study have implications for the enforcement of preventive and control measures aimed to reduce the prevalence of this parasite in endemic areas. Our georeferenced distribution of Rhipicephalus spp. occurrences support the fact that warmer climates and moisture-rich regions could be suitable for the potential distribution this parasite. In addition, these results demonstrate a reliable performance of the prediction model algorithm (Maxent) for this species according to our dataset. Findings support further geographical planning of preventive measures to interfere with the establishment of this parasite in areas that are ecologically suitable for its establishment and development.

\section{References}

Aguilar-Tipacamú G, Rodriguez-Vivas RI, 2003. Effect of moxidectin against natural infestation of the cattle tick Boophilus microplus (Acarina: Ixodidae) in the Mexican tropics. Vet Parasitol 111:211-6.

Aguilar-Tipacamú G, Rosario-Cruz R, Miller RJ, Guerrero FD, Rodriguez-Vivas RI, García-Vázquez Z, 2011. Phenotype changes inherited by crossing pyrethroid susceptible and resistant genotypes from the cattle tick Riphicephalus (Boophilus) microplus. Exp Appl Acarol 54:301-11.

Alegria-Lopez MA, Rodriguez-Vivas RI, Torres-Acosta JF, OjedaChi MM, Rosado-Aguilar JA, 2015. Use of ivermectin as endoparasiticide in tropical cattle herds generates resistance in gastrointestinal nematodes and the tick rhipicephalus microplus (Acari: Ixodidae). J Med Entomol 52:214-21.

Alonso-Díaz MA, García L, Galindo-Velasco E, Lezama-Gutierrez R, Angel-Sahagún CA, Rodríguez-Vivas RI, Fragoso-Sánchez H, 2007a. Evaluation of Metarhizium anisopliae (Hyphomycetes) for the control of Boophilus microplus (Acari: Ixodidae) on naturally infested cattle in the Mexican tropics. Vet Parasitol 147:336-40.

Alonso-Díaz MA, López-Silva BJ, MLAC L, Rodríguez-Vivas RI, 2007b. Natural infestation of Boophilus microplus Canestrini, 1887 (Acari: Ixodidae) in two cattle genotypes in the humid tropic of Veracruz, Mexico. Quehacer Científico Chiapas 38:503-9.

Alvarez JA, Ramos JA, Rojas EE, Mosqueda JJ, Vega CA, Olvera AM, Figueroa JV, Cantó GJ, 2004. Field challenge of cattle vaccinated with a combined Babesia bovis and Babesia bigemina frozen immunogen. Ann NY Acad Sci 1026:277-83.

De Clercq EM, Estrada-Peña A, Adehan S, Madder M, Vanwambeke SO, 2013. An update on distribution models for Rhipicephalus microplus in West Africa. Geospat Health 8:301-8.

De Clercq EM, Leta S, Estrada-Peña A, Madder M, Adehan S, Vanwambeke SO, 2015. Species distribution modelling for Rhipicephalus microplus (Acari: Ixodidae) in Benin, West Africa: comparing datasets and modelling algorithms. Prev Vet Med 118:8-21.

Dormann CF, Elith J, Bacher S, Buchmann C, Carl G, Carré G, Marquéz JRG, Gruber B, Lafourcade B, Leitão PJ, Münkemüller T, McClean C, Osborne PE, Reineking B, Schröder B, Skidmore AK Zurell D, Lautenbach S, 2013. Collinearity: a review of methods to deal with it and a simulation study evaluating their performance. Ecography 36:27-46.

Estrada-Peña A, 1999. Geostatistics and remote sensing using NOAA-AVHRR satellite imagery as predictive tools in tick distribution and habitat suitability estimations for Boophilus microplus (Acari: Ixodidae) in South America. National Oceanographic and Atmosphere Administration-Advanced Very High Resolution Radiometer. Vet Parasitol 81:73-82.

Estrada-Peña A, 2001. Climate warming and changes in habitat suitability for Boophilus microplus (Acari: Ixodidae) in Central America. J Parasitol 87:978-87.

Estrada-Peña A, Alexander N, Wint GR, 2016. Perspectives on modelling the distribution of ticks for large areas: so far so good? Parasit Vectors 9:179.

Estrada-Peña A, Bouattour A, Camicas JL, Guglielmone A, Horak I, Jongejan F, Latif A, Pegram R, Walker AR, 2006a. The known distribution and ecological preferences of the tick subgenus Boophilus (Acari: Ixodidae) in Africa and Latin America. Exp Appl Acarol 38:219-35.

Estrada-Peña A, García Z, Sánchez HF, 2006b. The distribution and ecological preferences of Boophilus microplus (Acari: Ixodidae) in Mexico. Exp Appl Acarol 38:307-16.

Estrada-Peña A, Venzal JM, 2006. High-resolution predictive mapping for Boophilus annulatus and B. microplus (Acari: Ixodidae) in Mexico and Southern Texas. Vet Parasitol 142:350-8.

Fand BB, Kumar M, Kamble AL, 2014. Predicting the potential geographic distribution of cotton mealybug Phenacoccus solenopsis in India based on MAXENT ecological niche model. J Environ Biol 35:973-82.

Fernández-Salas A, Rodríguez-Vivas RI, Alonso-Díaz M, 2012a. 
Resistance of Rhipicephalus microplus to amitraz and cypermethrin in tropical cattle farms in Veracruz, Mexico. J Parasitol 98:1010-4.

Fernández-Salas A, Rodríguez-Vivas RI, Alonso-Díaz MA, 2012b. First report of a Rhipicephalus microplus tick population multi-resistant to acaricides and ivermectin in the Mexican tropics. Vet Parasitol 183:338-42.

Fernández-Salas A, Rodríguez-Vivas RI, Alonso-Díaz MA, Basurto-Camberos H, 2012c. Ivermectin resistance status and factors associated in Rhipicephalus microplus (Acari: Ixodidae) populations from Veracruz, Mexico. Vet Parasitol 190:210-5

Galaviz-Silva L, Pérez-Treviño KC, Molina-Garza ZJ, 2013. Distribution of ixodid ticks on dogs in Nuevo León, Mexico, and their association with Borrelia burgdorferi sensu lato. Exp Appl Acarol 61:491-501.

García E, 1981. Modificaciones al sistema de clasificación climática de Köppen para adaptarlo a las condiciones de la República Mexicana. México: UNAM.

Gaxiola CSM, 2008. Dinámica poblacional de garrapatas del género Boophilus microplus en bovinos del estado de Sinaloa. Universidad Nacional Autónoma de México, México: D.F.

Gaxiola-Camacho S, García-Vázquez Z, Cruz-Vázquez C, Portillo-Loera J, Vázquez-Peláez C, Quintero-Martínez MT, Rosario-Cruz R, 2009. Comparison of efficiency and reproductive aptitude indexes between a reference and field strains of the cattle tick Rhipicephalus (Boophilus) microplus, in Sinaloa, Mexico. Rev Bras Parasitol Vet 18:9-13.

Giles JR, Peterson, AT, Busch JD, Olafson PU, Scoles GA, Davey RB, Pound JM, Kammlah DM, Lohmeyer KH, Wagner DM, 2014. Invasive potential of cattle fever ticks in the southern United States. Parasit Vectors 7:189.

Hijmans RJ, Cruz M, Rojas E, Guarino L, 2001. DIVA-GIS, version 1.4. A geographic information system for the management and analysis of genetic resources data.

Johnson TL, Bjork JK, Neitzel DF, Dorr FM, Schiffman EK, Eisen RJ, 2016. Habitat Suitability Model for the Distribution of Ixodes scapularis (Acari: Ixodidae) in Minnesota. J Med Entomol 53:598-606.

Jonsson NN, Bock RE, Jorgensen WK, 2008. Productivity and health effects of anaplasmosis and babesiosis on Bos indicus cattle and their crosses, and the effects of differing intensity of tick control in Australia. Vet Parasitol 155:1-9.

Khatchikian C, Sangermano F, Kendell D, Livdahl T, 2011. Evaluation of species distribution model algorithms for finescale container-breeding mosquito risk prediction. Med Vet Entomol 25:268-75.

Leta S, De Clercq EM, Madder M, 2013. High-resolution predictive mapping for Rhipicephalus appendiculatus (Acari: Ixodidae) in the Horn of Africa. Exp Appl Acarol 60:531-42.

Lohmeyer KH, Pound JM, May MA, Kammlah DM, Davey RB, 2011. Distribution of Rhipicephalus (Boophilus) microplus and Rhipicephalus (Boophilus) annulatus (Acari: Ixodidae) infestations detected in the United States along the Texas/Mexico border. J Med Entomol 48:770-4.

Lopez M, Figueroa JV, Ramos JA, Mosqueda JJ, Rojas E, Vega CA, Alvarez JA, 2008. Infection and seroconversion of susceptible animals introduced into a babesiosis endemic area. Ann NY Acad Sci 1149:131-5.

Manjunathachar HV, Saravanan BC, Kesavan M, Karthik K, Rathod P, Gopi M, Tamilmahan P, Balaraju BL, 2014.
Economic importance of ticks and their effective control strategies. Asian Pacific J Trop Dis 4:S770-9.

McQuillan MA, Rice AM, 2015. Differential effects of climate and species interactions on range limits at a hybrid zone: potential direct and indirect impacts of climate change. Ecol Evol 5:5120-37.

Miller RJ, Almazán C, Ortíz-Estrada M, Davey RB, George JE, De León AP, 2013. First report of fipronil resistance in Rhipicephalus (Boophilus) microplus of Mexico. Vet Parasitol 191:97-101.

Mondal DB, Sarma K, Saravanan M, 2013. Upcoming of the integrated tick control program of ruminants with special emphasis on livestock farming system in India. Ticks Tick Borne Dis 4:1-10.

Morales FM, 2014. Fundamento teórico de soporte para realizar el análisis de riesgo sobre la movilización de cepas de garrapata Boophilus spp. con resistencia a ixodicidas de zonas en fase de control. Facultad de Estudios Superiores Cuautitlán, Universidad Nacional Autónoma de México, Cuautitlán Izcalli, México.

Oliveira SV, Romero-Alvarez D, Martins TF, Santos JPD, Labruna MB, Gazeta GS, Escobar LE, Gurgel-Gonçalves R, 2017. Amblyomma ticks and future climate: Range contraction due to climate warming. Acta Trop 176:340-8.

Padilla O, Rosas P, Moreno W, Toulkeridis T, 2017. Modeling of the ecological niches of the Anopheles spp in Ecuador by the use of geo-informatic tools. Spat Spatiotemporal Epidemiol 21:1-11.

Phillips SJ, Dudík M, Elith J, Graham CH, Lehmann A, Leathwick J, Ferrier S, 2009. Sample selection bias and presence-only distribution models: implications for background and pseudoabsence data. Ecol Appl 19:181-97.

Phillips SJ, Dudík M, Schapire RE, 2006. Maxent software for modeling species niches and distributions (Version 3.4.1).

Pound JM, George JE, Kammlah DM, Lohmeyer KH, Davey RB, 2010. Evidence for role of white-tailed deer (Artiodactyla: Cervidae) in epizootiology of cattle ticks and southern cattle ticks (Acari: Ixodidae) in reinfestations along the Texas/Mexico border in south Texas: a review and update. J Econ Entomol 103:211-8.

Pérez de León AA, Teel PD, Auclair AN, Messenger MT, Guerrero FD, Schuster G, Miller RJ, 2012. Integrated strategy for sustainable cattle fever tick eradication in USA is required to mitigate the impact of global change. Front Physiol 3:195.

Qin H, Gao X, Wang H, Xiao J, 2016. Relative importance of meteorological and geographical factors in the distribution of Fasciola hepatica infestation in farmed sheep in Qinghai province, China. Parasite 23:59.

Raghavan RK, Goodin DG, Hanzlicek GA, Zolnerowich G, Dryden MW, Anderson GA, Ganta RR, 2016. maximum entropy-based ecological niche model and bio-climatic determinants of lone star tick (Amblyomma americanum) niche. Vector Borne Zoonotic Dis 16:205-11.

Rodriguez-Vivas RI, Domínguez-Alpizar J, 1998. Grupos entomológicos de importancia veterinaria en Yucatán, México. Rev Biomed 9:26-37.

Rodriguez-Vivas RI, Grisi L, Pérez de León A, Silva V, TorresAcosta J, Fragoso S, Romero S, Rosario C, Saldierna F, García C, 2017. Potential economic impact assessment for cattle parasites in Mexico. Review. Rev Mex Cienc Pecu 8:67-74.

Rodriguez-Vivas RI, Hodgkinson JE, Rosado-Aguilar JA, 
Villegas-Perez SL, Trees AJ, 2012. The prevalence of pyrethroid resistance phenotype and genotype in Rhipicephalus (Boophilus) microplus in Yucatan, Mexico. Vet Parasitol 184:221-9.

Rodriguez-Vivas RI, Li AY, Ojeda-Chi MM, Trinidad-Martinez I, Rosado-Aguilar JA, Miller RJ, Pérez de León AA, 2013. In vitro and in vivo evaluation of cypermethrin, amitraz, and piperonyl butoxide mixtures for the control of resistant Rhipicephalus (Boophilus) microplus (Acari: Ixodidae) in the Mexican tropics. Vet Parasitol 197:288-96.

Rodriguez-Vivas RI, Trees AJ, Rosado-Aguilar JA, Villegas-Perez SL, Hodgkinson JE, 2011. Evolution of acaricide resistance: phenotypic and genotypic changes in field populations of Rhipicephalus (Boophilus) microplus in response to pyrethroid selection pressure. Int J Parasitol 41:895-903.

Rodríguez SD, García Ortiz MA, Jiménez Ocampo R, Vega y Murguía CA, 2009. Molecular epidemiology of bovine anaplasmosis with a particular focus in Mexico. Infect Genet Evol 9:1092-101.

Rodríguez-Vivas RI, Miller RJ, Ojeda-Chi MM, Rosado-Aguilar JA, Trinidad-Martínez IC, Pérez de León AA, 2014a. Acaricide and ivermectin resistance in a field population of Rhipicephalus microplus (Acari: Ixodidae) collected from red deer (Cervus elaphus) in the Mexican tropics. Vet Parasitol 200:179-88.

Rodríguez-Vivas RI, Pérez-Cogollo LC, Rosado-Aguilar JA, Ojeda-Chi MM, Trinidad-Martinez I, Miller RJ, Li AY, de León AP, Guerrero F, Klafke G, 2014b. Rhipicephalus (Boophilus) microplus resistant to acaricides and ivermectin in cattle farms of Mexico. Rev Bras Parasitol Vet 23:113-22.

Rodríguez-Vivas RI, Rivas AL, Chowell G, Fragoso SH, Rosario CR, García Z, Smith SD, Williams JJ, Schwager SJ, 2007. Spatial distribution of acaricide profiles (Boophilus microplus strains susceptible or resistant to acaricides) in southeastern Mexico. Vet Parasitol 146:158-69.

Rosado-Aguilar JA, Rodriguez-Vivas RI, Garcia-Vazquez Z, Fragoso-Sanchez H, Ortiz-Najera A, Rosario-Cruz R, 2008. Development of amitraz resistance in field populations of Boophilus microplus (Acari: Ixodidae) undergoing typical amitraz exposure in the Mexican tropics. Vet Parasitol 152:349-53.

Rosario-Cruz R, Guerrero FD, Miller RJ, Rodriguez-Vivas RI, Tijerina M, Dominguez-Garcia DI, Hernandez-Ortiz R, Cornel AJ, McAbee RD, Alonso-Diaz MA, 2009. Molecular survey of pyrethroid resistance mechanisms in Mexican field populations of Rhipicephalus (Boophilus) microplus. Parasitol Res
$105: 1145-53$

SAGARPA, 2012. Acuerdo por el que se establece la Campana Nacional para el control de la garrapata Boophilus spp. Diario Oficial de la Federacion.

SENASICA, 2017. Informes Zoosanitarios Semanales, Mexico City, Mexico, Servicio Nacional de Sanidad, Inocuidad y Calidad Agroalimentaria.

Solorio-Rivera JL, Rodríguez-Vivas RI, Pérez-Gutierrez E, Wagner G, 1999. Management factors associated with Babesia bovis seroprevalence in cattle from eastern Yucatán, Mexico. Prev Vet Med 40:261-9.

St John HK, Adams ML, Masuoka PM, Flyer-Adams JG, Jiang J, Rozmajzl PJ, Stromdahl EY, Richards AL, 2016. Prevalence, distribution, and development of an ecological niche model of dermacentor variabilis ticks positive for Rickettsia montanensis. Vector Borne Zoonotic Dis 16:253-63.

Stevens KB, Pfeiffer DU, 2011. Spatial modelling of disease using data- and knowledge-driven approaches. Spat Spatiotemporal Epidemiol 2:125-133.

Suwannatrai A, Pratumchart K, Suwannatrai K, Thinkhamrop K, Chaiyos J, Kim CS, Suwanweerakamtorn R, Boonmars T, Wongsaroj T, Sripa B, 2017. Modeling impacts of climate change on the potential distribution of the carcinogenic liver fluke, Opisthorchis viverrini, in Thailand. Parasitol Res 116:243-50.

Sánchez GK, 2014. Diagnóstico de la susceptibilidad de Rhipicephalus (Boophilus) microplus a ivermectinas en Unidades de Producción Bovina de la zona centro de Veracruz, Ver. Facultad de Medicina Veterinaria y Zootecnia, Universidad Veracruzana, Veracruz, México.

Treviño MR, 2013. Evaluación de resistencia a ixodicidas y efectividad de la vacuna bm86 en el grado de infestacion por garrapata Boophilus sp. en las razas de ganado bovino Charolais, Simmental, Brangus negro y comercial. Universidad Autónoma de Nuevo León, Escobedo, N.L., México.

Wang HH, Corson MS, Grant WE, Teel PDC, 2017. Quantitative models of Rhipicephalus (Boophilus) ticks: historical review and synthesis. Ecosphere 8:e01942-n/a.

Wang Y, Yu X, Cao J, Zhou Y, Gong H, Zhang H, Li X, Zhou J, 2015. Characterization of a secreted cystatin from the tick Rhipicephalus haemaphysaloides. Exp Appl Acarol 67:289-98.

Williams HW, Cross DE, Crump HL, Drost CJ, Thomas CJ, 2015. Climate suitability for European ticks: assessing species distribution models against null models and projection under AR5 climate. Parasit Vectors 8:440. 